\title{
UMA ANÁLISE DOS REFLEXOS DEIXADOS PELA DEGRADAÇÃO AMBIENTAL DOS PERÍODOS ECONÔMICOS DO SÉCULO XVIII E XIX EM SILVA JARDIM, RJ
}

\section{An analysis of reflections left by the environmental degradation of the economics periods from the XVIII Century to the XIX century in Silva Jardim, RJ}

Thais Gulias Oliveira Mestranda pelo programa de Pós-Graduação em Geografia e Meio Ambiente na PUC- RIO tha.gulias@ hotmail.com

Artigo enviado para publicação em 27/12/2018 e aceito em 20/06/2019

DOI: 10.12957/tamoios.2019.39149

\section{Resumo}

Os primeiros relatos sobre o Município de Silva Jardim datam de meados do século XVIII, onde recebia o nome de Capivari, porém há grandes controvérsias sobre sua origem. Crescendo meio ao bioma de Mata Atlântica. Localizado na região das Baixada Litorânea do Rio de Janeiro, microrregião da bacia do Rio São João. O presente artigo visa analisar a história de ocupação e crescimento através da exploração de recursos naturais dos períodos econômicos de exploração madeireira e agrícola do bioma de Mata Atlântica na passagem do século XVIII para o século XIX em Silva Jardim. E pontuar que esses impactos se refletem até hoje na paisagem fragmentada que recebe tentativas de recuperação.

Palavras chaves: Mata Atlântica, História Ambiental, Preservação Ambiental, Baixada Litorânea.

\begin{abstract}
The first reports about the Municipality of Silva Jardim date from the middle of the XVIII century, where it was called Capivari, but there are great controversies about its origin. Growing between the Atlantic Forest Biome, located in the coastal lowlands region of Rio de Janeiro, a microregion of the São João river basin. The present article aims to analyze the history of occupation and growth through the natural resources of the economic periods of logging and agricultural exploitation of the Atlantic Forest biome from the XVIII century to the XIX century in Silva Jardim. It should be noted that these impacts are reflected even today in the fragmented landscape that receives recovery attempts.
\end{abstract}

Keywords: Atlantic Forest, Environmental History, Environmental Preservation, Lowland Coastal. 


\section{Introdução}

Os primeiros relatos sobre o Município de Silva Jardim datam de meados do século XVIII, porém há grandes controvérsias sobre sua origem. Localizado na região das Baixada Litorânea do Rio de Janeiro, microrregião da bacia do Rio São João, apresenta limites territoriais com diversos municípios: ao norte de Nova Friburgo, ao sul Araruama, a leste Casimiro de Abreu, a oeste Rio Bonito e a noroeste Cachoeiras de Macacu. Localizada a altitude de 35 metros do nível do mar, coordenadas geográficas 22 graus 39' 03" latitude sul e 42 graus 23' 30" longitude oeste. Divide seu território em quatro distritos: Silva Jardim-sede, Aldeia Velha, Gaviões e Correntezas (IBGE, 2012).

Tendo sua área urbana ocupando apenas 0,4 \% do município, essa ocupação territorial é caracterizada, majoritariamente, por pequenas propriedades rurais dedicadas às atividades agropecuárias (Embrapa, 2001).

O município chama atenção por possui grande parte de seu território protegido por reservas ambientais devido à preocupação com a preservação da Mata Atlântica que foi muito explorada principalmente no século XVIII e XIX. E a proteção do mico-leãodourado, sendo considerada uma espécie bandeira por sua atratividade (aparência) e carisma junto ao público, o conhecimento prévio pela população da espécie e de sua vulnerabilidade e importância ecológica, papel de polinizador, fundamental para regeneração da floresta. Assim dando destaque para a Reserva Biológica de Poço das Antas, no distrito de Aldeia Velha, por realizar o trabalho de proteção e manejo, contribuído para a formação de um corredor e a interligação de florestas para garantir a biodiversidade da região (Procópio de Oliveira Et. AL, 2008).

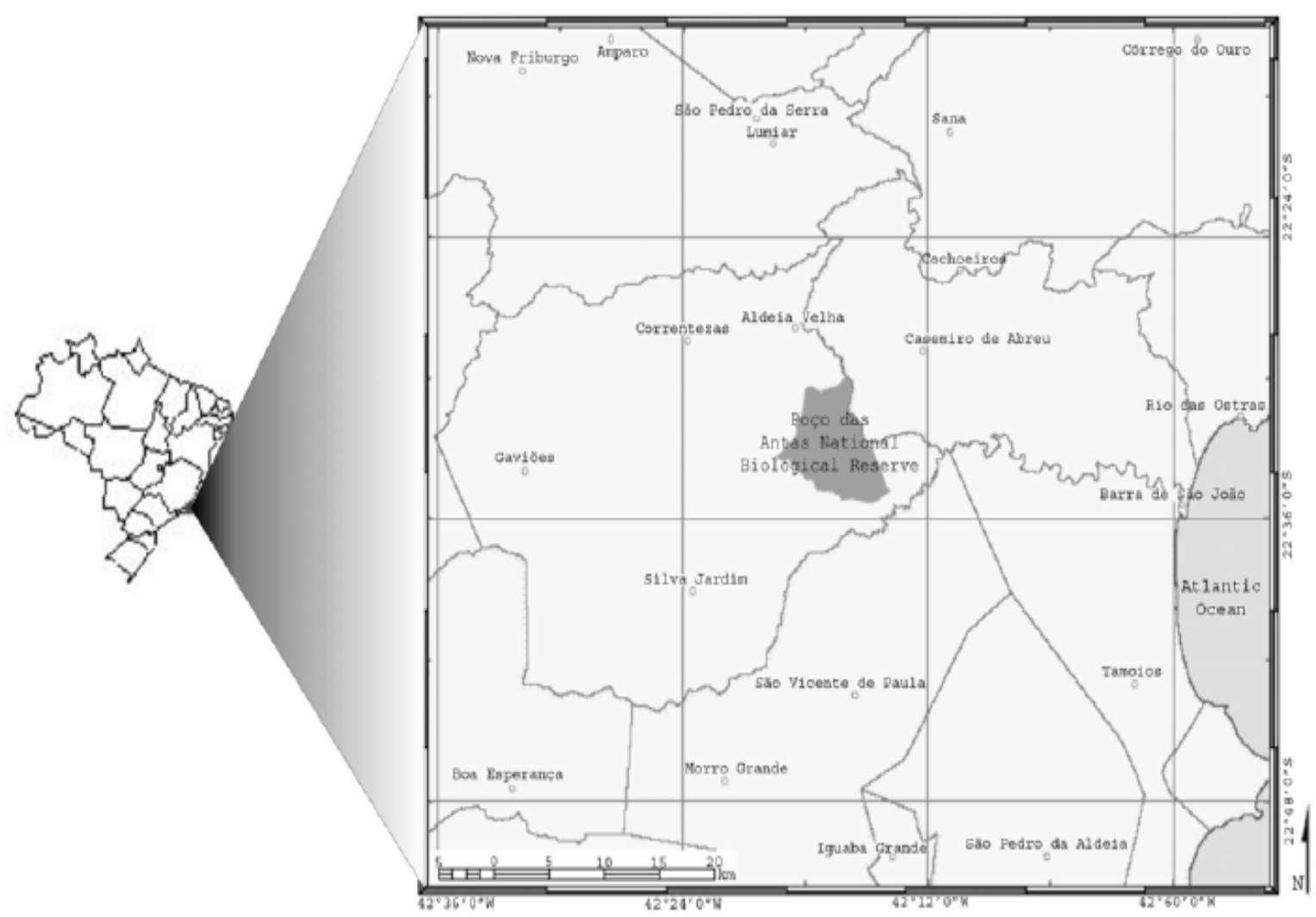

Figura 1 Mapa da área de estudo. Silva Jardim, Rio de Janeiro. (MMA/IBAMA, 2007) 


\section{Um breve histórico de Silva Jardim}

O primeiro histórico bibliográfico sobre Silva Jardim, antes chamado de Capivari, aconteceu no "Diccionario geographico, historico e descriptivo, do Imperio do Brazil" de J. C. R. Milliet de Saint-Adolphe, publicado em 1845, onde nas páginas 237 e 238 encontra- se:

"Capivari. Nova villa e antiga freguesia da provincia do Rio de Janeiro, comarca de Cabo Frio, cabeça de collegio eleitoral. Uma capella edificada por Maria Rodrigues, no passado século, era a única igreja que se achava num vasto território situado entre a cordilheira dos Aimorés, e o rio Bacaxá, mas a povoação tendo-se augmentado, edificou-se largo tempo depois outra igreja da ivocação de N.S da Lapa, e o Bispo do Rio de Janeiro lhe conferio o titulo de freguesia por provisão do mez d' Outubro de 1810 . Uma lei provineial de 8 de maio de 1841 elevou esta freguesia á categoria de villa. Seu districto, desmembrado da cidade de Cabo frio, se compõe no território de fraguezia, e do das aldeas velhas e novas d' Ipuca, e se extende ao norte pela cordilheira dos Aimorés, até a da Nova Friburgo; a oeste, confronta com os territórios das freguesias de Trindade e Rio Bonito; ao sul, o rio Bracacaxá o separa do districto da cidade de Cabo- Frio; e a leste, fica contiguo com o da villa de Macahé. Em 1835 apenas se contavam 2,000 almas neste distrito, mas actualmente passarão de 3,000. A indústria principal da gente d'elle, além da agricultação dos gencros do paiz, consiste no corte e preparação de madeiras de construcçao; Taboado, etc., que vão por agua pelos ribeiros e canaes, até o rio de São- João, d' onde são transportados em barcos para o Rio de Janeiro." (SaintAdolphe, 1845, pág. 237 e 238)

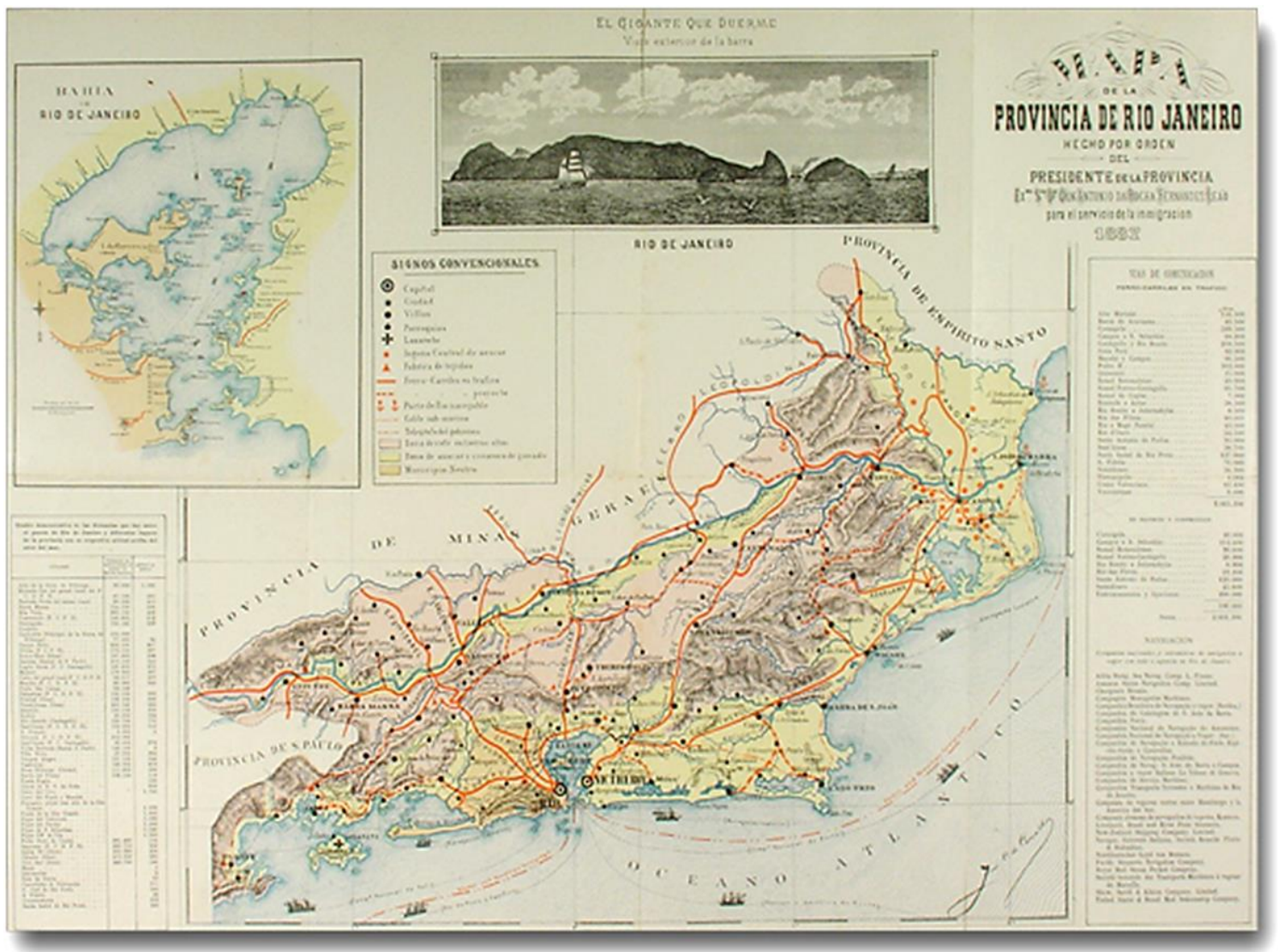

Figura 2 Carvalho, J. C. Mapa de la Província de Rio de Janeiro. Gravura colorida com a legenda" Mapa de la Provincia de Rio de Janeiro hecho por ordem del Presidente de la exmo. Sr. Don Antonio da Rocha Fernandes Leão para el servicio de la inmigracion”. 53 x 74 cm. 1887. 
Porém, o surgimento de Silva Jardim vai anteceder ao seu título de freguesia. Em "Como era verde o meu vale..." um estudo arqueológico de Paulo Seda em Gaviões, distrito de Silva Jardim, publicado em 2013. Deixa claro como os vestígios do mundo rural do século XIX contém muitos marcos não relatados de uma história rica e densa do município.

Na primeira metade do século XVIII, foi fundada uma ermida juntamente com um aldeamento de índios Guarulhos sob a condução do capuchinho italiano Frei Francisco Maria de Todi. Com a degradação da ermida, se optou por buscar outro local para sua construção e assentar o aldeamento, o local escolhido foi às margens do rio São João. Anos depois a administração da capela construída e do aldeamento fica na responsabilidade dos padres seculares, esse não demostra, interesse pelo local o que provoca a desconcentração dos índios, em consequência o fim do aldeamento. Isso levou ao repartimento e distribuição dessas terras para colonos que as requeriam (Seda, 2013).

Na segunda metade do século XVIII, nas margens da Lagoa de Juturnaíba, foi erguida a capela de N.S. da Lapa de Capivari. Ainda nesse período na fazenda de Manoel Azevedo e D. Maria Rodrigues, foi fundada uma capela dedicada a Santana e esse teria sido o marco da ocupação do povoado de Capivari, para alguns. Os moradores desse povoado foram conquistando a montante do rio São João, atraídos pela abundância de madeiras-de-lei e pela fertilidade do solo adequado ao desenvolvimento da agricultura. As incursões rio acima deram origem a novos povoados, entre eles: Capivari, Poço das Antas, Correntezas e Gaviões. O município e a cidade de Silva Jardim tiveram origem em um destes novos povoados, o de Capivari (Seba, 2013).

Em 1828, no Regime das Câmaras Municipais de João Baptista Cortines Laxe, conta que com crescimento no povoado de Capivari, seus habitantes lutavam pela elevação de seu povoamento a categoria de Freguesia, buscando maior autonomia em relação a seu subordinado a Cabo Frio. Então, em 9 de outubro de 1801 foi fundada a Freguesia de Nossa Senhora da Lapa de Capivari.

A produção agrícola da região, principalmente a produção de cana-de açúcar, café e cereais, trouxe crescimento e desenvolvimento (Seba, 2013). Assim pela Lei $\mathrm{n}^{\circ} 239$, em 8 de maio de 1841, Nossa Senhora da Lapa de Capivari ganha o título de Vila. Em 6 de janeiro de 1843, providenciando-se a construção de uma Câmara, cadeia pública e cemitério, em terras doadas por Luiz Gomes. Nessa época, a localidade já tinha atingido um grau bem elevado de comércio e era bastante populosa para os padrões de então, vivendo praticamente da lavoura, onde o braço escravo era fundamental. Possuía bons estabelecimentos comerciais, botica e movimento no porto construído no rio São João. Além da lavoura, dedicava-se à exportação de madeira e minérios, atividades que forneciam bons lucros (Abreu, 1994).

Em 1881, os trilhos da Estrada de Ferro Leopoldina chegaram à região de Silva Jardim aumentando o movimento e as possibilidades de crescimento, além do escoamento da produção que antes era realizado apenas de forma fluvial por cabotagem ao longo do rio São João (Abreu, 1994). 


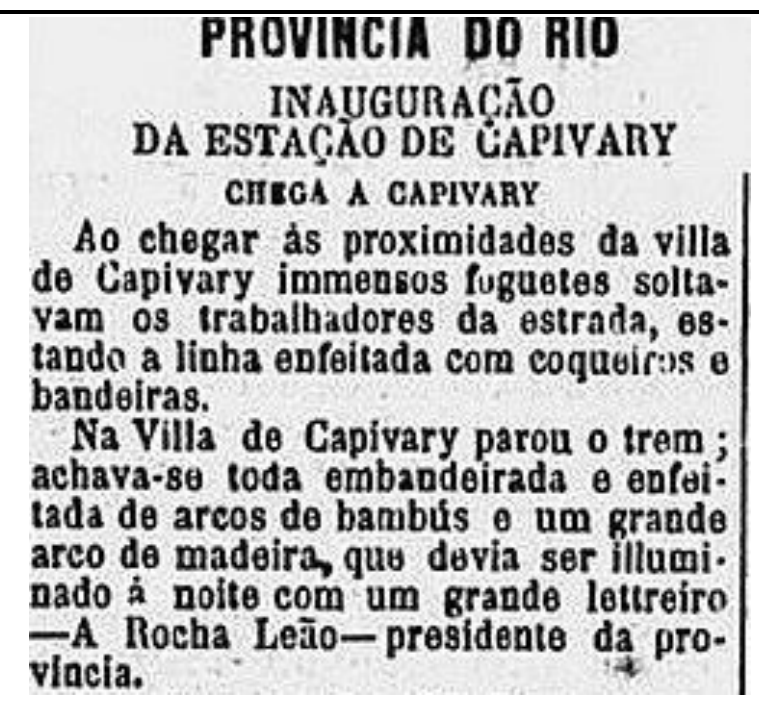

Figura 3 A inauguração da estação de Capivary foi reportada e descrita pelo jornal em 1986 - (Diário de Notícias, 19/10/1886)

Os dias de bonança não foram muito longe, pois com a assinatura da Lei Áurea, em 1888, os escravos libertos deixaram as plantações, abandonando a área rural e migrando para cidades maiores. Nesse mesmo período algumas das famílias de imigrantes suíços e alemães, que haviam inicialmente se estabelecido na região de Nova Friburgo, aproveitando a disponibilidade e a desvalorização das terras abandonadas, tomaram os caminhos que ligavam a serra à baixada e ali criaram os povoados de Aldeia Velha e Juturnaíba. Anos depois muitos moradores perderam ou venderam suas terras para grandes proprietários, extinguindo a vida dos distritos e provocando grande evasão rural. Havia também casos de malária (impaludismo) que ocorriam no verão e ocasionavam muitas mortes na região (Abreu, 1994).

A vila de Capivari recebeu foros de cidade em janeiro de 1890 , no período republicano, assim permanecendo até 31 de dezembro de 1943.

No Governo Vargas pelo decreto-lei estadual no 1056, de 31-12-1943, o município de Capivari passou a denominar- se Silva Jardim, em homenagem ao seu filho ilustre, o poeta Antônio da Silva Jardim (Abreu, 1994).

Com a drenagem dos locais afetados, por volta de 1947, o problema foi exterminado. Nos anos 50, foram construídas estradas de rodagem entre os distritos e entre os municípios vizinhos. A construção da BR-101, que passa a $5 \mathrm{~km}$ da cidade, tornou-a acessível a visitantes e viajantes de muitas outras localidades. Mais tarde foi construída a barragem da Lagoa de Juturnaíba, que abastece de água vários municípios, e executado o saneamento do Rio São João (Abreu, 1994).

\section{Caracterização Ambiental}

De acordo com Bergallo, 2009, a Região da Baixada Litorânea é caracteriza-se por colinas, maciços costeiros e baixadas. Nestas últimas, observam-se formações diversas tais como planícies aluviais, em muitos trechos de brejo. A cobertura vegetal original do território dessa região era constituída principalmente por Mata Atlântica e por formações típicas das áreas aluviais (vegetação herbácea).

O município de Silva Jardim apresenta um quadro geomorfológico complexo e diferenciado em razão da morfogênese. As diferentes combinações morfoestruturais e morfológicas respondem pela existência de regiões ambientais distintas. Neste contexto 
observa-se a existência dos domínios: Escarpas da Serra dos Órgãos, Colinas e Maciços Costeiros, e Planícies Costeiras (Coe, 2007).

$\mathrm{Na}$ serra do Mar são observadas escarpas abruptas, originadas por falhas escalonadas. A topografia do maciço Litorâneo é constituída por um planalto dissecado, de relevo diversificado. A baixada é composta por pequenas elevações onde estão situados os maiores trechos dos rios que formam a bacia do Rio São João e onde estão depositadas as terras de maior fertilidade, formadas por aluviões trazidos pelos rios cujas cabeceiras encontram-se na serra do Mar e nos maciços do litoral. Observa-se ainda a presença de terras-baixas de difícil drenagem (Coe, 2007).

Os solos são caracterizados como de médio e elevado grau de intemperização, com reações ácida e levemente neutra, forte presença de ferro, mica, berilo e calcários, e ocorrência, ainda, de feldspato e quartzo na rocha de origem, materiais observados também no baixo curso do rio São João onde repousam sedimentos aluvianos e restingas marinhas (Coe, 2007).

A Bacia do Rio São João, onde se localiza o divisor de águas, a Serra do Mar, possui grande parte do seu território coberto por fragmentos e maciços florestais remanescentes da Mata Atlântica, além de abrigar importantes ecossistemas de água doce. Percorre uma distância de $150 \mathrm{~km}$ até desaguar no oceano Atlântico, em seu percurso a maior parte é ocupada por amplas planícies fluviomarinhas, sobre grande influência do mar, permitindo assim, a penetração da cunha salina por vários quilômetros para o interior do Rio São João (Oliveira e Mello, 2007; Drummond, 2008). O rio São João nasce na cota aproximada de 900 metros, no divisor entre suas águas e as do rio Macaé; os afluentes principais são os rios Bacaxá e Capivari. Merecem ainda destaque na formação da bacia os rios Águas Claras, Aldeia Velha, Bananeiras, Crubixás, Maratuã, do Ouro, da Prata, Pilões, Pirineus, São Lourenço, Taquarussús e Vargem Grande (Oliveira e Mello, 2007; Wasserman et Al. 2008).

Os solos são mais férteis nos vales formados pelos rios, que com sua planura realizam um fenômeno semelhante ao processo natural de inundação a que é submetido o rio Nilo, no Egito. As inundações regulares que ocorriam na estação chuvosa e que deixavam o rico material orgânico fertilizante dos solos. Um dos corpos hídricos de maior destaque da região é a lagoa de Juturnaíba, situada em uma extensa planície conhecida no passado por baixada de Araruama (Wasserman et Al. 2008).

Grande parte da região, principalmente na serra, é coberta pela Mata Atlântica e protegida pela Reserva da Biosfera da Mata Atlântica, homologada pela Organização das Nações Unidas para a Educação, a Ciência e a Cultura-UNESCO, em 1992 (MMA, 2008).

No plano Municipal de Conservação e Recuperação da Mata Atlântica- Silva Jardim mostra que os principais usos e cobertura do solo da região da Baixada Litorânea são por: 
Tabela 1 Caracterização de uso do solo na região da Baixada Litorânea. (CILSJ, 2007)

\begin{tabular}{|c|c|}
\hline Uso / Cobertura do Solo & Conceito \\
\hline Área Agrícola (AA) & Terra utilizada para a produçăo de alimento \\
\hline Área Inundâvel (AI) & Terrenos que margeiam rios e sujeitos a inundaçăo no periodo de cheia \\
\hline Afloramento Rochoso (AR) & $\begin{array}{l}\text { Area com alta declividade ou topo de morro e vegetação composta de } \\
\text { gramíneas, bromelias e pteridófitas }\end{array}$ \\
\hline Área urbana (AU) & $\begin{array}{l}\text { Compreendem áreas de uso intensivo, estruturadas por edificaçסes e } \\
\text { sistema viário }\end{array}$ \\
\hline Campos de Altitude (CA) & $\begin{array}{l}\text { Vegetaçào típica dos ambientes montano e alto montano, com estrutu- } \\
\text { ra arbustiva e ou herbácea que ocorre no cume de serra com altitudes } \\
\text { elevadas }\end{array}$ \\
\hline Campo/Pastagem (CP) & $\begin{array}{l}\text { Areas destinadas ao pastoreio do gado, formadas mediante plantio de } \\
\text { forragens perenes. Nestas áreas o solo está coberto por vegetaçăo de } \\
\text { gramineas ou leguminosas }\end{array}$ \\
\hline Floresta Estacional (FE) & $\begin{array}{l}\text { Estrutura florestal com perda das follhas dos estratos superiores duran- } \\
\text { te a estaçao desfavorável - seca e frio }\end{array}$ \\
\hline Floresta Ombrofila (FO) & $\begin{array}{l}\text { Floresta que ocorre em ambientes sombreados onde a umidade } e \text { alta e } \\
\text { constante ao longo do ano (Resoluçăo CONAMA 012/94) }\end{array}$ \\
\hline Mangue (M) & $\begin{array}{l}\text { Ecossistema costeiro, de transiçao entre os ambientes terrestre e mari- } \\
\text { nho, característico de regiōes tropicais e subtropicais: }\end{array}$ \\
\hline Praia (P) & Faixa de areia na orla maritima \\
\hline Restinga (R) & $\begin{array}{l}\text { Conjunto das comunidades vegetais, fisionomicamente distintas, sob } \\
\text { influendia marinha e fluvio-marinha }\end{array}$ \\
\hline Reflorestamento (RF) & Plantio de espécies florestais nativas e exóticas \\
\hline Rios, Lagos (RL) & Curso de águas naturais \\
\hline Salinas (S) & Area destinada a produção de sal \\
\hline Solo Exposto (SE) & Solo degradado, não possui a camada orgänica \\
\hline Vegetaçăo em recuperaçăo (VR) & $\begin{array}{l}\text { Vegetaçào secundária com predomínio de espécies pioneiras, área pro. } \\
\text { xima a fragmentos florestais }\end{array}$ \\
\hline Vegetaçăo de vắrzea (V) & Vegetaçào localizada nas planicies de inundação \\
\hline
\end{tabular}

A vegetação da Região da Bacia do São João constitui-se por um conjunto de diferentes fragmentos, refletindo a inclinação e a orientação das encostas, a profundidade do solo e mesmo o tempo decorrido dos processos antrópicos de exploração vegetal. Há ainda tipos rasteiros de vegetação, que aparecem em tufos sobre as escarpas. Sendo possível encontrar exemplares de essências florestais que no passado faziam parte da cobertura vegetal nativa da região, entre elas o cedro (Cedrella spp.), o jequitibá-rosa (Cariniana sp.), sapucaia (Portulaca oleracea), tapinhoã (Ocotea odorifera), ipê (Tebebuia spp.), braúna (Melaoxylon brauna),vinhático (Planthymenia sp.) (MMA, 2008). Estruturas de grande porte que chamaram a atenção para a exploração e extração de madeira nessa região. 
O território onde se localizam os remanescentes florestais da Mata Atlântica que cobrem grande parte do relevo e parte da baixada, nesse domínio, nos locais onde a vegetação ainda mantém condições originais, podem ser encontrados muitos grupos de mico-leão dourado (Leontopitecus rosalia), poucas e solitárias preguiças-de-coleira (Bradypus torquatus), além de muitas outras espécies de animais silvestres (.MMA, 2008; Procópio de Oliveira Et. al, 2008). A prova disso é que Silva Jardim possui o maior porcentual de vegetação natural preservada na região da Baixada Litorânea como pode se observar na tabela da Fundação SOS Mata Atlântica de 2014.

Tabela 2. Porcentagem de Mata Atlântica em municípios abrangidos pela floresta (Lei da Mata Atlântica), ano-base 2014. Destaque para o município de Silva Jardim, RJ. (SOS Mata Atlântica, 2014)

\begin{tabular}{|c|c|c|c|c|c|c|c|c|c|}
\hline Municípios & $\begin{array}{c}\text { Área } \\
\text { municipal }\end{array}$ & $\begin{array}{l}\text { Area } \\
\text { da Lei }\end{array}$ & $\begin{array}{l}\% \\
\text { Lei }\end{array}$ & Mata & Restinga & Mangue & $\begin{array}{l}\text { Veg. de } \\
\text { Vârzea }\end{array}$ & $\begin{array}{l}\text { Veg. } \\
\text { Natural }\end{array}$ & $\begin{array}{c}\% \\
\text { de Veg. } \\
\text { Natural }\end{array}$ \\
\hline Araruama & 63.405 & 63.405 & $100 \%$ & 1,744 & 288 & & 352 & 2.384 & $4 \%$ \\
\hline $\begin{array}{l}\text { Armação } \\
\text { dos Búzios }\end{array}$ & 7.093 & 7.093 & 10096 & 413 & 1.134 & & & 1.547 & $22 \%$ \\
\hline $\begin{array}{l}\text { Arraial } \\
\text { do Cabo }\end{array}$ & 15.396 & 15.396 & 10096 & 163 & 811 & & & 974 & 646 \\
\hline Cabo Frio & 40.275 & 40.275 & $100 \%$ & 1.162 & 1.660 & 83 & 293 & 3.198 & $8 \%$ \\
\hline $\begin{array}{l}\text { Casimiro } \\
\text { de Abreu }\end{array}$ & 46.226 & 46.226 & $100 \%$ & 14.059 & 51 & 90 & & 14.200 & $31 \%$ \\
\hline $\begin{array}{l}\text { Iguaba } \\
\text { Grande }\end{array}$ & 5.162 & 5.162 & $100 \%$ & 51 & 47 & & & 98 & $2 \%$ \\
\hline Maricá & 36.365 & 36.365 & $100 \%$ & 7.637 & 369 & & & 8.006 & $22 \%$ \\
\hline Rio Bonito & 46.154 & 46.154 & $100 \%$ & 6.877 & & & & 6.877 & $15 \%$ \\
\hline $\begin{array}{l}\text { Rio } \\
\text { das Ostras }\end{array}$ & 23.141 & 23.141 & $100 \%$ & 3.172 & 105 & 74 & 32 & 3.382 & $15 \%$ \\
\hline $\begin{array}{l}\text { São Pedro } \\
\text { da Aldeia }\end{array}$ & 34.154 & 34.154 & $100 \%$ & 778 & 1.154 & & 221 & 2.153 & $6 \%$ \\
\hline Saquarema & 35.612 & 35.612 & $100 \%$ & 4.653 & 302 & & 907 & 5.862 & $16 \%$ \\
\hline Silva Jardim & 93.846 & 93.846 & $100 \%$ & 31.517 & & & 253 & 31.769 & $34 \%$ \\
\hline
\end{tabular}

O clima da região é classificado como tropical quente e úmido com temperaturas médias anuais entre 18 e 32 graus Celsius. $\mathrm{O}$ verão é quente, opressivo, com precipitação e de céu encoberto; o inverno é agradável, úmido e de céu quase sem nuvens. Tendo grande chamariz turístico nos meses de maio a setembro, por possuir um clima agradável. O total pluviométrico registrado de médio anual é de 1435,3 $\mathrm{mm}$. Os meses mais chuvosos sendo janeiro, novembro e dezembro, com $662,2 \mathrm{~mm}$, correspondendo a $46 \%$ da chuva anual. Os meses mais secos são junho, julho e agosto, com 122,2 mm correspondendo a 8,5\% da chuva anual (Santos, 2009).

\section{Recursos Naturais X Crescimento Econômico}

Como já citado acima todo o crescimento e interesse por Silva Jardim, antiga Capivari, ocorre pela possível exploração de seus recursos naturais. Pois o estado do Rio 
de Janeiro está inserido em sua totalidade no bioma de Mata Atlântica, sendo uma zona de alta diversidade de fauna e flora, além de ricos recursos hídricos.

Segundo Dean em Ferro e Fogo, 2004, a história da Mata Atlântica é uma história de perdas porque em todo mundo ao longo dos anos a história das florestas está muito ligada à destruição em prol de enriquecimento ou ocupação. Afinal para aos homens europeus não havia um sentido de lugar naquelas sociedades compostas por inúmeras espécies de plantas e animais em contínua interação. Seus conhecimentos não o possibilitavam viver em ambientes altamente hostis às suas necessidades como de fato é uma floresta tropical. Para permanecer lá, o homem branco, precisava alterar aquela paisagem para sua melhor habitação e lucro. Assim, para viver na Mata Atlântica os homens, necessariamente, precisaram destrui-la. Foi este o caso dos portugueses que chegaram ao Continente Sul Americano no século XV. “(...) não parece errado dizer que, na América portuguesa, as pessoas viam a floresta basicamente como uma utilidade material" (Carvalho, 2012).

No início do século XVI, e posteriormente prosseguiu em escalas abruptas a ocupação, exploração e consequentemente a alteração da vegetação natural nesse bioma. As causas são bem conhecidas: a extração de pau-brasil; a demanda de grossos lenhos para as numerosas e imensas caldeiras de derretimento da gordura de baleias; a procura de combustível lenhoso em geral para uso da crescente população; o corte de madeirasde-lei para construção naval e civil; a derrubada, queimada e limpeza de extensas áreas florestais para fins de pecuária, agricultura e, a ocupação de terrenos para o estabelecimento e desenvolvimento de povoados, vilas e cidades (Dean, 2004).

"A Coroa portuguesa sempre demonstrou entender que o sucesso fiscal de sua colônia americana dependia do uso das suas abundantes matas. Quem não tem cão, caça com gato e a decepção inicial na procura de metais preciosos fez-la realizar que a floresta era tudo que ela tinha nessas terras distantes." (Carvalho, 2012)

No século XVIII, se inicia a grande corrida para o interior em busca de riquezas. A mata nativa da região era abundante em madeiras-de-lei e o rio São João tornou-se fator importante no desbravamento e no desenvolvimento regional de Silva Jardim, além de facilitar o acesso rumo ao interior da baixada e o abastecimento, funcionava também como via de escoamento da produção agrícola e de lenha para os portos. Visto que na Europa ocorria a Revolução Industrial, que buscava matéria-prima para além de suas fronteiras, levando a Inglaterra a se voltar para outros mercados, favorecendo então o Brasil.

Uma vez devastada a floresta, o campo estava pronto para plantação que pela fertilidade do solo se adequou muito bem ao desenvolvimento da agricultura. Assim, a madeira cedeu lugar ao café e à cana-de-açúcar e o enriquecimento dos fazendeiros da região foi ainda mais relevante.

\footnotetext{
"Mas o que os agricultores prezavam, na verdade, eram as próprias árvores, ou melhor, a cinza proveniente de sua queima. Evidentemente, as arvores eram utilizadas também como madeira, mas apenas marginalmente em caráter comercial. Um dos mais famosos manuais agrícolas do século XIX, escrito por Luiz Peixoto de Lacerda Werneck (Barão de Pati do Alferes), aconselhava os fazendeiros a plantarem café em terras onde cresciam árvores como o jacarandá e outras excelentes espécies madeireiras típicas de floresta primaria." (Carvalho, 2012)
}

No século XIX, os trilhos da Estrada de Ferro Leopoldina chegaram à região de Silva Jardim aumentando o movimento e as possibilidades de crescimento. A cultura do 
café era sua mais importante atividade agrícola, seguida pela cana-de-açúcar e cereais cultivados na baixada.

“A importância do seu porto e da Estrada de Ferro Central do Brasil potencializava o mercado muito acima da população da cidade, pois as mercadorias eram distribuídas através de cabotagem (...) Para o interior, os trilhos das estradas de ferro asseguravam o fornecimento de amplas regiões." (Levy, 1994)

No entanto, esse desenvolvimento econômico não permaneceu mais do que um século. A extinção das matas, assim como a exaustão dos solos, aliados à escassez de mão de obra decorrente da abolição da escravatura fizeram com que Capivari (Silva Jardim) entrasse em colapso no final do século XIX (Abreu, 1994).

\section{Considerações Finais}

A história de desenvolvimento de Silva Jardim está atrelada a seu bioma, a Mata Atlântica, essa que foi o atrativo para ocupação e exploração da região desde sua fundação. Ao mesmo tempo em que trazia riqueza ao homem, selava a esperança da fauna e flora a sua sobrevivência em meio à predação do crescimento econômico.

A devastação da região pelos períodos da madeira e da agricultura principalmente nos séculos XVIII e XIX criou uma paisagem severamente fragmentada onde através dos trabalhos de conscientização e manejo realizados pelas áreas de proteção ambiental juntamente com a parceria dos grandes proprietários possibilitam a recuperação local. Neste cenário, é inegável a importância destes remanescentes e restauração da conectividade entre eles, criando corredores, para assegurar a conservação da biodiversidade dos processos ecológicos na área que é de relevante ocorrência do micoleão-dourado que atualmente é uma espécie bandeira na conservação da Mata Atlântica.

\section{REFERÊNCIAS BIBLIOGRÁFICAS}

ABREU, A. I. C. Municípios E Topônimos Fluminenses. História E Memória. Niterói: Imprensa Oficial Do Estado Do Rio De Janeiro, 1994.

Anuário Estatístico Do Estado Do Rio De Janeiro. Rio De Janeiro: Fundação Ceperj, 2013.

BERGALLO, H. G. ET AL. Estratégias e ações para a conservação da biodiversidade no estado do Rio de Janeiro. Rio de Janeiro: Instituto Biomas, 2009.

BOHRER, C. B A. ET AL. Mapeamento da vegetação e uso do solo no centro de diversidade vegetal de Cabo Frio, Rio de Janeiro, Brasil. Rodriguésia, Rio de Janeiro, v. 60, n. 1, p. 001-023, 2009.

BRASIL. Mata atlântica e campos sulinos. In: biodiversidade brasileira vol. 5. Avaliação e identificação de áreas e ações prioritárias para a conservação, utilização sustentável e repartição dos benefícios da biodiversidade dos biomas brasileiros. Brasília: mma, 2002.

BRUZZI, N. Casimiro de Abreu. Aurora. Brasil, 1949. 
CABRAL, D. O 'Bosque de Madeiras' e outras histórias: a Mata Atlântica no Brasil Colonial (séculos XVIII e XIX). Tese de doutorada- UFRJ. Rio de Janeiro, 2012.

CABRAL, D; CESCO, S. Notas Para Uma História na Exploração Madeireira na Mata Atlântica Do Sul-Sudeste Ambiente \& Sociedade, Vol. XI, Núm. 1, janeiro-junho. Campinas, 2008.

COE, H. ET AL. Peculiaridades Ecológicas da Região De Cabo Frio, RJ julho/ dezembro-Ano IV, N. 2, 2007.

DEAN, W. A Ferro E Fogo: A História e a Devastação da Mata Atlântica Brasileira. 1. Ed. São Paulo: Cia. das letras, 2004.

GUERRA, A. T. Dicionário Geológico-Geomorfológico. 7 Ed. Rio De Janeiro: IBGE, 1989.

HONORATO, C; MANTUANO, T. M. A Economia da Região Portuária do Rio de Janeiro (1870-1900). Nuevo Mundo Mundos Nuevos [Online], 2016.

IBAMA. Unidades De Conservação do Brasil, Vol. 1 - Parques Nacionais e Reservas Biológicas. Brasília: Ibama, 1989.

IBGE. Silva Jardim. Enciclopédia dos Municípios Brasileiros, Vol 22. Rio De Janeiro: IBGE, 1959.

IBGE. Indicadores De Desenvolvimento Sustentável. Diretoria de Geociências. Rio de Janeiro: IBGE, 2002.

IBGE. Censo 2010. Rio de Janeiro: IBGE, 2010.

INSTITUTO CHICO MENDES DE CONSERVAÇÃO DA BIODIVERSIDADE. Plano de Manejo da Área de Proteção Ambiental da Bacia do Rio São João/Mico-Leão-Dourado. Brasília: MMA, 2008

LAXE, J. B. C. Regimento das Câmaras Municipais ou Lei de $1^{\circ}$ de outubro de 1828 . E. \& H. Laemmert. Rio de Janeiro. 1868.

LEVY, M. B. A Indústria do Rio de Janeiro Através de Suas Sociedades Anónimas, Rio de Janeiro, Editora UFRJ/Secretaria Municipal De Cultura, 1994.

LOPES, R. S; ABRAHÃO, J. Plano Municipal de Conservação e Recuperação da Mata Atlântica de Silva Jardim / Secretaria de Estado do Ambiente. Rio de Janeiro, 2017.

OLIVEIRA, F. LS; MELLO, E. F. A Mineração de Areia e os Impactos Ambientais na Bacia do Rio São João, RJ. Revista Brasileira De Geociência, 2007.

PROCÓPIO DE OLIVEIRA, P. ET. AL. Conservação do Mico-Leão-Dourado: Enfrentando Os Desafios de uma paisagem Fragmentada. Campos dos Goytacazes: Universidade Estadual Do Norte Fluminense Darcy Ribeiro; Centro De Biociências E Biotecnologia; Laboratório De Ciências Ambientais, 2008. 
$\overline{\text { SAINT-ADOLPHE, J. C. R. M. Diccionario Geographico, Historico e Descriptivo, do }}$ Imperio do Brazil. J. P. Aillaud. França, 1845.

SANTOS, N. M. Análise da Influência da Cobertura do Solo Sobre os Valores das Variáveis Físicas da Atmosfera em Diferentes Localidades no Estado do Rio de Janeiro. Monografia de Engenharia Florestal. UFRRJ, 2009

SEDA, P. "Como Era Verde o Meu Vale..." Pedras, Louças, Vidros, Cachimbos: Vestígios do Mundo Rural no Rio de Janeiro no Século XIX. [UERJGEO] Interações Homem.Indb. Rio de Janeiro, 2013.

WASSERMAN, J. C. ET AL. Viabilidade de Utilização dos Recursos Hídricos da Bacia do Rio São João para o Complexo Petroquímico do Rio De Janeiro. UFF, 2008. 